\title{
Correlation of HBA1C with UACR and Serum Creatinine Level in Type 2 Diabetes Mellitus
}

\section{Hawale D', Ambad R ${ }^{2}$, Hadke $S^{3}$, Anjankar A4}

\author{
'Tutor Department of Biochemistry Jawaharlal Nehru Medical College, Datta Meghe Institute of Medical Sciences Sawangi (Meghe) Ward- \\ ha-442001, India; ${ }^{2}$ Associate Professor Department of Biochemistry Datta Meghe Medical College, Nagpur-441110, India; ${ }^{3}$ Assistant Professor \\ Department of Medicine Datta Meghe Medical College, Nagpur-441110, India; ${ }^{4}$ Associate Professor, Department of Biochemistry Jawaharlal \\ Nehru Medical College, Datta Meghe Institute of Medical Sciences Sawangi (Meghe) Wardha-442001, India.
}

\section{ABSTRACT}

Introduction: Diabetes mellitus (DM) is a major emerging clinical health problem in this world. It is a clinical syndrome characterized by hyperglycaemia due to absolute or relative deficiency of insulin. Type 2 DM comprises about $90 \%$ of the diabetic population of any country. Diabetic nephropathy is a chronic microvascular complication of poorly controlled diabetes mellitus (DM), leading to end-stage renal disease (ESRD). Diabetic nephropathy is estimated to turn into the most frequent cause of ESRD in the developing world. About $20 \%$ to $30 \%$ of people with either type 1 or type 2 diabetes develop nephropathy, whose incidence increases with the duration of diabetes.

Objective: To check the association of $\mathrm{HbA1c}$ (a marker for glycemic control) \& two early markers of renal functional impairments: ACR (reflection of MA) serum creatinine in Type 2DM.

Methods: This study was a case-control study, conducted in the Medicine Department at DMMC \& SMHRC, Nagpur in collaboration with ABVRH, Sawangi (Meghe) from September 2020 to November 2020. In the present study, the total number of subjects included was 100 having an age group between 41-70. The subjects were grouped into two types Group 1: 50 (control) Healthy Individuals Group 2: 50 (study) Type 2 diabetes mellitus

Results: In the present study mean levels of HbA1c, microalbumin, serum creatinine and UACR were significantly increased in the study group as compared to the control group and also find a correlation of glycosylated Haemoglobin with UACR and serum creatinine levels in type 2 diabetes mellitus patient.

Conclusions: Raised $\mathrm{HbA1c}$ is associated with urinary ACR. Urinary ACR should be estimated in monitoring risk assessment of Type 2DM in patients with raised HbA1C.

Key Words: HbA1c, U. ACR (Albumin: Creatinine Ratio), serum creatinine, Type 2 DM

\section{INTRODUCTION}

Diabetes mellitus is described by chronic hyperglycemia due to carbohydrate, fat, and protein metabolism disturbances. Absolute or relative deficits in insulin secretion, insulin action, or both are associated with diabetes mellitus. ${ }^{1}$

In India, the prevalence of diabetic nephropathy ranges from $32 \%$ to $57 \%$ and overt proteinuria is found in $5 \%$ to $28 \%$ of diabetic patients. ${ }^{2}$ Diabetes mellitus contributes to a third of all patients in dialysis units in India. Diabetic nephropathy is a major public health problem because most diabetic patients in India have almost entirely unavailable dialysis and kidney transplantation therapy. ${ }^{3,4}$ According to the International Diabetes Federation (IDF) in 2013, 382 million people worldwide had diabetes, in which type 2 made up about $90 \%$ of the cases. This is equivalent to $8.3 \%$ of the adult people with equal rates in both men and women. More than $80 \%$ of diabetic patient's deaths obtain in little and middle-income countries. The number of groups with diabetes is estimated to rise to 592 million by $2035 ., 6$

The leading cause of chronic kidney disease (CKD) in the United States and other western societies is diabetic nephropathy. In the United States, diabetes is responsible for $30-40 \%$ of all ESRD cases. ${ }^{6}$ India currently has an approximate overall incidence rate of $\mathrm{CKD}$ and end-stage renal disease (ESRD) of 800 per million population (pmp) and 150200 pmp, respectively. It was noted that DM was detected in $31.2 \%$ of patients as the cause of CKD. The measurement of

\section{Corresponding Author:}

Dr. Ranjit Ambad, Associate Professor Dept. of Biochemistry, Datta Meghe Medical College, Nagpur-441110, India. Mob: 9917999919; Email: ambad.sawan@gmail.com

ISSN: 2231-2196 (Print)

Received: 12.02 .2021
ISSN: 0975-5241 (Online)

Revised: 09.04 .2021
Accepted: 13.05 .2021
Published: 04.06 .2021 
urine microalbumin levels has become the gold standard for tracking the development of diabetic nephropathy and is also predictive of elevated levels of $\mathrm{HbA1C}{ }^{7}$

Type 2 DM comprises about $90 \%$ of the diabetic population of any country. A chronic microvascular complication of poorly regulated diabetes mellitus (DM) is diabetic nephropathy, leading to end-stage renal disease (ESRD). ${ }^{8}$ Diabetic nephropathy is estimated to turn into the most frequent cause of ESRD in the developing world. About 20\% to $30 \%$ of people with either type 1 or type 2 diabetes develop nephropathy, whose incidence increases with the duration of diabetes. ${ }^{9,10,11}$ Micro albuminuria significantly increases the relative risk of development of diabetic nephropathy and is a risk factor for adverse cardiovascular outcomes. ${ }^{12,13}$

Diabetes is a major cause of morbidity and mortality throughout the world especially more alarming in developing countries. Diabetes is among the leading causes of kidney failure and screening for early signs of diabetes-related to kidney disease is a cost-saving intervention and feasible for developing countries. Microvascular complications including nephropathy, retinopathy and neuropathy are initiated by chronic hyperglycemia.

MA (microalbumin) is an early marker of reversible nephropathy, can identify very early stages of progressive glomerular disease. Early detection of diabetic nephropathy relies on tests for urinary excretion of albumin. There are two methods used to determine urinary albumin excretion: 24 hours AER (Albumin Excretion Rate) \& spot urine ACR..${ }^{14}$ Serum creatinine is primarily a metabolite of creatine, almost all of which is located in skeletal muscle. The normal level of creatinine is 0.8 to $1.4 \mathrm{mg} / \mathrm{dL}$. Females usually have a lower creatinine ( 0.6 to $1.2 \mathrm{mg} / \mathrm{dL}$ ) than males, because they usually have less muscle mass. ${ }^{15}$ The quantity of creatine per skeletal muscle mass unit is consistent and the creatine breakdown rate is also consistent. Thus, plasma creatinine concentration is very stable and a direct reflection of skeletal muscle mass. ${ }^{16}$ Skeletal muscle is a major target tissue of insulin and a lower volume of skeletal muscle would mean fewer target sites for insulin which causes an increase in insulin resistance. This leads to the development of type 2 diabetes. ${ }^{17}$

Monitoring for glycemic control \& Screening for MA and timely therapeutic intervention has become the standard of diabetic care worldwide. This study was designed to see the association of $\mathrm{HbAlc}$ (a marker for glycemic control) \& two early markers of renal functional impairments: ACR (reflection of MA) serum creatinine in Type 2DM.

\section{MATERIALS AND METHODS}

\section{Study design}

This study was a case-control study, conducted in the Medicine Department at DMMC \& SMHRC, Nagpur in collaboration with ABVRH, Sawangi (Meghe) from September 2020 to November 2020.

\section{Study population}

In the present study, the total number of subjects included was 100 having an age group between 41-70. The subjects were grouped into the following two types:

I. Group 1: 50 (control) Healthy Individuals

II. Group 2: 50 (study)Type 2 diabetes mellitus

\section{Inclusion criteria for Type 2 Diabetes Mellitus}

The following criteria were taken into consideration while characterizing the subjects as Type -2 Diabetes as per WHO

1. $\mathrm{FBS}>126 \mathrm{mg} / \mathrm{dl}$ on more than one occasion.

2. 2 hours PP level $>200 \mathrm{mg} / \mathrm{dl}$.

3. Both fasting and PP levels are above these values on the same occasion.

4. HbA1C levels more than $6.5 \%$ of the average threemonth assessment.

\section{Exclusion criteria for Type 2 Diabetes Mellitus}

Patients suffering from chronic disorders like

1. Tuberculosis

2. HIV.

3. liver Cirrhosis, Acute \& chronic kidney failure.

\section{Sample Collection}

Blood was collected from each subject by venipuncture with standard blood collection technique in a plain vial for serum separation and EDTA vial for HbA1C estimation. The urine sample was be collected in a sterile container with a preservative (Boric Acid).

\section{Biochemical Analysis ${ }^{18-21}$}

Glycosylated haemoglobin was estimated by the HPLC method. Urinary Microalbumin was estimated by the immune Turbidometry method. Urine creatinine and serum creatinine was estimated by modified Jaffe's method. Spot Urinary ACR (UACR) calculated by calculation.

\section{Statistical analysis}

The data were analyzed using the SPSS software program, version 20.0. The mean and standard deviation were measured. Analyzed and interpreted using descriptive and inferential statistics. The correlations of HbA1c with urinary ACR and serum creatinine were calculated by Pearson's correlation test and the relevant ' $p$ ' value was calculated as level of significance. The probability value is less than $0.05(\mathrm{p}<0.05)$ and it was considered statistically significant.

\section{RESULT}

Table 1 shows percentage-wise distribution of control group and study group. The present study includes a total of 100 
subjects. Total 100 subjects were divided into two groups: the Control Group consists of 50 (50\%)) Healthy Individu- als and the study group consists of $50(50 \%)(\mathrm{T} 2 \mathrm{DM} \mathrm{Pa}-$ tients).

Table 1: Percentage-wise distribution of subjects in Control Group \& Study Group

\begin{tabular}{|c|c|c|c|}
\hline Sr. No. & Groups & No. of patients & Percentage (\%) \\
\hline 1 & Control group (Healthy Individuals) & 50 & 50 \\
\hline 2. & Study group (T2DM Patients) & 50 & 50 \\
\hline & & 100 & 100 \\
\hline
\end{tabular}

Table 2 shows the gender-wise distribution of healthy control and study group. The present study includes a total of 100 subjects. The Control group consists of 18 males (36\%) and 32 female (64\%). The study group consists of 25 males $(50 \%)$ and 25 females $(50 \%)$

Table 2: Gender wise distribution of subjects in Control group (Healthy individuals), Study group (T2DM patients)

\begin{tabular}{lcccccc} 
Groups & Male & Percentage & Female & Percentage & Total & Percentage \\
$\begin{array}{l}\text { Control group } \\
\text { (Healthy Individuals) }\end{array}$ & 18 & $(36 \%)$ & 32 & $(64 \%)$ & 50 & $(100 \%)$ \\
$\begin{array}{l}\text { Study group } \\
\text { (T2DM Patients) }\end{array}$ & 25 & $(50 \%)$ & 25 & $(50 \%)$ & 50 & $(100 \%)$ \\
\hline
\end{tabular}

Table 3 shows that the mean levels of HbAlc, microalbumin, serum creatinine and UACR were significantly increased in the study group as compared to the control group.

Table 3: Comparison of Mean levels of HbA1c, Microalbumin serum creatinine \&UACR in control group (Healthy Controls) and study group (T2DM)

\begin{tabular}{|c|c|c|}
\hline Parameter & $\begin{array}{l}\text { Control Group Healthy Individuals } \\
\text { Mean } \pm \text { SD }\end{array}$ & Study Group (Diabetes Mellitus) Mean \pm SD \\
\hline $\mathrm{HbAl}_{\mathrm{C}}(\%)$ & $5.27 \pm 0.87$ & $7 \cdot 30 \pm 0.61^{* *}$ \\
\hline Microalbumin mg /l & $16.27 \pm 12.10$ & $102.72 \pm 81.90^{* *}$ \\
\hline Serum Creatinine (mg/dl) & $0.91 \pm 0.40$ & $1.20 \pm 0.60^{*}$ \\
\hline UACR mg/g & $18.20 \pm 10.88$ & $163.30 \pm 110.0^{* *}$ \\
\hline
\end{tabular}

${ }^{*} \mathrm{P}<0.05$ (significant), ${ }^{* *} \mathrm{p}<0.001$ (highly significant)

Table 4: Correlation between HbA1c with Microalbumin, serum creatinine \& UACR in the study group (T2DM)

\begin{tabular}{clc} 
Sr. No. & Parameters & $\begin{array}{c}\text { Group 2 } \\
\text { (r-value) }\end{array}$ \\
o1 & HbAic with Microalbumin & $0.62^{* *}$ \\
02 & HbAic with serum creatinine & $0.41^{*}$ \\
03 & HbAic with UACR & $0.44^{*}$ \\
\hline
\end{tabular}

"p $\leq 0.05$ significant, ${ }^{* *} \mathrm{p} \leq 0.001$ highly significant

\section{DISCUSSION}

The present study aim was to assess levels of $\mathrm{HbAlc}$, microalbumin, and urine and serum creatinine in diabetes patients and healthy individual and also find an association of glycosylated $\mathrm{Hb}$ with UACR and serum creatinine levels in type 2 diabetes mellitus patient. In the present study, we found mean levels of $\mathrm{HbAlc}$, microalbumin and serum creatinine levels were significantly increased in study groups as compared to the control group. In the present study mean levels of urinary ACR were significantly increased in diabetes patient compared to control \& We found a significant positive correlation of UACR with HbA1c in Diabetic patients $(\mathrm{r}=0.44)$. 
Haque $\mathrm{N}$ et al. has also reported a significant positive correlation of $\mathrm{HbAlc}$ with $\mathrm{S}$. creatinine and urinary ACR in type 2 diabetic patients ( $p$ values are 0.008 and $<0.001$ ) respectively. ${ }^{22}$ Similar studies were reported by Sheik et al. They have found a significant positive correlation of $\mathrm{HbAlc}$ with microalbuminuria $(p<0.05)$ and serum creatinine $(p<0.001)$ in type $2 \mathrm{DM}$ patients. ${ }^{23}$ Several interesting studies about Diabetes were reported. ${ }^{24-27}$ Khanna et. al. reported a study of serum uric acid levels in acute stroke. ${ }^{28}$ Sanyukta et al. reported on the association of Spot Urinary Albumin Creatinine Ratio (UACR) with Coronary Artery Disease. ${ }^{29}$ Ambad et al. reported about the Relationship between Uric Acid and Creatinine in Pre-Diabetic and Diabetic Patients..$^{30}$ Few of the diabetes-related studies were reviewed. ${ }^{31-34}$ Walinjkar et al. studied platelet indices as a predictor of microvascular complications in type 2 diabetes. ${ }^{35}$ Warjukar et al. conducted a study of microalbuminuria and uric acid in type 2 diabetes mellitus. ${ }^{36}$ Study of Carotid Intima-Media Thickness in Prediabetes and Its Correlation with Cardiovascular Risk Factors was done by Bhinder et al. ${ }^{37}$

The present study shows a statistically significant positive correlation of HbAlc with urinary microalbumin, Serum Creatinine \& albumin to creatinine ratio. It indicates as the level of glycosylated haemoglobin increases, it causes increased urinary microalbumin excretion. Hyperglycemia increases glycation of proteins and that may lead to the formation and accumulation of harmful advanced glycation end products and oxidative stress, which might be related to early kidney function impairment and increased urine albumin-tocreatinine ratio in type 2 diabetes mellitus patients.

\section{CONCLUSION}

The present study shows a statistically significant positive correlation of HbAlc with urinary microalbumin, S.Cr \& UACR. It indicates as the level of glycosylated haemoglobin increases; it causes increased urinary microalbumin excretion. Hyperglycemia increases glycation of proteins and that may lead to the formation and accumulation of harmful advanced glycation end products and oxidative stress, which might be related to early kidney function impairment.

\section{Conflict of interest: Nil}

Source of funding: Nil

Ethical clearance: Taken from the institutional ethics committee

\section{REFERENCES}

1. Kanwar G, Jain N, Sharma N, Shekhawat M, Ahmed J, Kabra R. Significance of Serum Urea and Creatinine Levels in Type 2 Diabetic Patients. J Dental Med Sci. 2015;14:65-7.
2. Sobngwi E, Mauvais-Jarvis F, Vexiau P. Diabetes in Africans. Part 1: Epidemiology and clinical specificities. Diab Metab. 2001;27:628-34.

3. Mbanya JC, Sobngwi E. Diabetes in Africa. Diabetes microvascular and macrovascular disease in Africa. J Cardiovasc Risk. 2003;10:97-102.

4. Levitt NS. Diabetes in Africa: epidemiology, management and healthcare challenges. Heart. 2008;94:1376-82.

5. Guariguata L, Nolan T, Beagley J. IDF Diabetes Atlas. 6th ed: International Diabetes Federation. 2013:12-3.

6. Sato F, Tamura Y, Watada H, Kumashiro N, Igarashi Y. Effects of diet-induced moderate weight reduction on intrahepatic and intramyocellular triglycerides and glucose metabolism in obese subjects. J Clinic Endocrino Metabol. 2007;92(8): 3326-29.

7. U.S. Renal Data System: USRDS 2008 Annual Data Report: Atlas of End-Stage Renal Disease in the United States. Bethesda, MD: National institute of diabetes and digestive and kidney diseases; 2008:1- 12.

8. Nazmin H, Bidhan CD, Mohammad I, Khondaker S, Monojit M, Shahadat $\mathrm{H}$. Association of HbA1c with urinary ACR and eGFR in type-2 diabetes mellitus. Pulse. 2011;5(1):6-11.

9. Barnett PS, Braunstein GD. Diabetes mellitus. In: Carpenter CCJ, Griggs RC, Loscalzo J, editors. Cecil's essentials of medicine. 6th ed. Philadelphia: Saunders. 2004:621-638.

10. Van Dijk C, Berl T. Pathogenesis of diabetic nephropathy. Rev Endocr Metab Disord. 2004;5:237-48.

11. Locatelli F, Canaud B, Eckardt KU. The importance of diabetic nephropathy in current nephrological practice. Nephrol Dial Transplant. 2003;18:1716-25.

12. Damsgaard, EM, Froland A, Jorgensen OD, Mogensen CE. Microalbuminuria is a predictor of increased mortality in elderly people. Br Med J. 1990;300:297-300.

13. Bhupesh M, Sumit KT, Maheep S, Bushra F. Association of Creactive protein with renal functions and microalbuminuria in type 2 diabetes mellitus. J Dental Med Sci. 2018;17(9):79-84.

14. Eknoyan G, Hostter T, Barkis GL. Proteinuria \& other markers of chronic kidney diseases: a position statement of the national kidney foundation (NKF), and the national institute of diabetes \& kidney disease (NIDDK). Am J Kid Dis. 2003;42(4):617-622.

15. Molitoris BA. Acute kidney injury. In Goldman L, Ausiello D, editors. Cecil Medicine. 23rd ed. Philadelphia, Pa: Saunders Elsevier, 2007: chap 121.

16. Martin RF. Renal Function. In Clin Chem Theory, Analysis, Correlation. 4th ed. Kaplan LA,Pesce AJ, Kazmierczak SC, editors. St. Louis, Missouri, Mosby, 2003: 483-484.

17. DeFronzo RA, Gunnarsson R, Björkman O, Olsson M, Wahren J. Effects of insulin on peripheral and splanchnic glucose metabolism in noninsulin-dependent (type II) diabetes mellitus. J Clin Invest. 1985;76:149-155.

18. American diabetes association. Standards of medical care for patients with diabetes mellitus. Diab Care. 2001;24 (1):33-4.

19. Bakker AJ, Mucke M. Gammopathy interference in clinical chemistry assays: mechanisms, detection and prevention. Clin Chem Lab Med. 2007;45(9): 1240-3.

20. Young DS. Effects of drugs on clinical laboratory tests. 5th ed. Washington, DC: The American Association for Clinical Chemistry. 2000:579-581.

21. CLSI. Evaluation of precision performance of quantitative measurement methods; approved Guideline- Second edition. CLSI document EP5-A2. USA. 2008:5-12.

22. Haque N, Debnath BC, Ibrahim M, Sirajuddin K, Majumder M, Hossain M S. Association of HbA1c with Urinary ACR and eGFR in type-2 diabetes mellitus. Pulse. 2011;5:6-11. 
23. Sheik S, Beig JA, Iqbal T, Kazmi T. Prevalence of microalbuminuria with relation to glycemic control in T2 diabetic patients in Karachi. J Ayub Med Coll Abbottabad. 2009;21(3):83-6.

24. Raja KK, Inamdar AH, Lahole S, Palsodkar P. Prevalence of Non-Alcoholic Fatty Liver Disease in Prediabetes and Diabetes. Int J Pharmac Res 2019;11(3):1424-27.

25. Ramani R, Banait S, Pawar M. A Study of Central Corneal Thickness and Corneal Endothelial Cell Changes in Type 2 Diabetes Mellitus with and without Diabetic Retinopathy: A Case Control Study. Int J Pharmac Res. 2019;11(1):1243-46.

26. Gupte Y, Acharya S, Kumar S, Patil PS. Assessment of Endothelial Function by Fmd (Flow Mediated Dilatation) in Prediabetes. Int J Pharmac Res. 2019;11(2):1808-12.

27. Hingnikar P, Bhola N, Jadhav A, Sharma N. Mucormycosis of Maxillary Sinus in a Newly Diagnosed Case of Diabetes Mellitus. J Datta Meghe Insti Med Sci Uni 2019;14(4):397-400.

28. Khanna S, Inamdar A, Kumar A, Basat AV. Study of Serum Uric Acid Levels in Acute Stroke. Int J Pharmac Res. 2019;11(4):2041-44.

29. Sanyukta H, Inamdar AH, Kumar S. Association of Spot Urinary Albumin Creatinine Ratio (UACR) with Coronary Artery Disease. Eur J Mol Clin Med. 2020;7(2):1962-66.

30. Ambad RS, Jha RK, Butola LK, Bankar N, Singh BR, Dhok A. Relationship between Uric Acid and Creatinine in Pre-Diabetic and Diabetic Patients: Vidarbha Region of Maharashtra. Int $\mathrm{J}$ Res Pharmac Sci. 2020;11(3):3412-17.
31. Shinde RV, Rana AP, Rajurkar H, Kaple MN. Prameha and Diabetes Mellitus. Int J Curr Res Rev. 2020;12(14):96-98.

32. Subhadarsanee C, Dhadse PV, Baliga V, Bhombe K. Coronavirus Disease and Diabetes - Interplay of Two Pandemics. Int J Pharmac Res. 2020;11(Special Issue 1):1048-53.

33. Unnikrishnan B, Rathi P, Bhat SK, Nayak PH, Ravishankar P, Singh A, Praveen O. Risk Factors of Gestational Diabetes Mellitus: A Hospital-Based Pair-Matched Case-Control Study in Coastal South India. South Afr J Obstet Gynaecol. 2020;26(1):13-17.

34. Wagh SP, Bhagat SP, Bankar N, Jain K. Role of Vitamin-c Supplementation in Type II Diabetes Mellitus. Int J Curr Res Rev. 2020;12(13):61-64.

35. Walinjkar RS, Khadse S, Kumar S, Bawankule S, Acharya S. Platelet Indices as a Predictor of Microvascular Complications in Type 2 Diabetes. Indian J Endocrinol Metab. 2019;23(2):20610.

36. Warjukar P, Jain P, Kute P, Anjankar A, Ghangale SS. Study of Microalbuminuria and Uric Acid in Type 2 Diabetes Mellitus. Int J Curr Res Rev 2020;12(14):56-65.

37. Bhinder HHPS, Kamble TK. The Study of Carotid IntimaMedia Thickness in Prediabetes and Its Correlation with Cardiovascular Risk Factors. J Datta Meghe Insti Med Sci Uni. 2018;13(2):79-82. 